\title{
Deslizamentos das mídias: textos de memória, livro de história e narrativa de história de vida em Ingrid, uma história de exílios ${ }^{1}$
}

\author{
Barbara Heller \\ Priscila Ferreira Perazzo
}

Resumo: Investigamos como as memórias transitam de uma mídia a outra, partindo, em ordem cronológica, do texto da memória (manuscritos e relatos orais) de Ingrid Koster para o texto do livro, Ingrid, uma história de exílios, publicado em 2010. Verificamos as adaptações, silenciamentos e acréscimos na construção dos textos da memória no livro, comparando-os nas diferentes mídias. Mostramos que as memórias e seus suportes midiáticos, cada vez mais deslizantes, são atravessados por esses acréscimos imaginados e documentados e por supressões de natureza emocional e política. Edward Said, com "exílios", Lucia Santaella, com "cultura midiática" e "deslizamentos", Beatriz Sarlo, com "memória" e "testemunha", Walter Benjamin, com "narrativa e cura" dão sustentação teórica à análise.

Palavras-Chave: memória; mídias; narrativas de história de vida.

Abstract: Medias' sliding: text memory, history book and life history narratives in Ingrid, uma história de exílios - We investigate how memories move from one media to another, starting, in chronological order, from the memory text (i.e. manuscripts and oral testimony) by Ingrid Koster and ending with the text of the book, Ingrid, uma história de exílios, published in 2010. We checked out the adjustments, the omissions and the additions made in the construction of memory texts in this book, comparing them in different medias. We demonstrate that memories and their medias, which are increasingly sliding one over other, are crossed by imagined and documented additions and by deletions of emotional and political nature. Edward Said's "exiles", Lucia Santaella's "media culture" and "slips", Beatriz Sarlo's "memory" and "witness" and Walter Benjamin's "narrative and healing" give theoretical support to the analysis.

Keywords: memory; media; life history narratives.

1 Trabalho apresentado no Grupo de Trabalho "Memória nas Mídias" do XXV Encontro Anual da Compós, na Universidade Federal de Goiás, Goiânia, de 7 a 10 de junho de 2016. 


\title{
Introdução
}

"Os fatos aconteceram exatamente como minha mente infantil imaginava, como em um conto de fadas". Essa é a frase que abre o manuscrito de Ingrid Koster, um relato de memória que ela escreveu já septuagenária, no qual denominaremos aqui, a partir de agora, texto da memória ${ }^{2}$. Esse texto confirma a intrínseca relação entre experiência e relato, enfatizada pelo advérbio "exatamente". A autora, tomada por suas lembranças, não percebe que aquilo que está para contar - a felicidade que sentiu quando sua mãe se casou com o homem que passou a considerar como pai - não eliminará o paradoxo criado entre sua certeza individual e o universo imaginário, coletivo e compartilhado por milhões de seres humanos ao redor do mundo ocidental, por adultos ou crianças, homens ou mulheres, ativado pela expressão "conto de fadas". A primeira pessoa, marcada pelo pronome pessoal "minha", indispensável quando não existem outros narradores, mais do que uma mera escolha de uma forma de discurso, expressa as condições culturais e políticas que o tornam crível (SARLO, 2007, p. 25).

Tanto isso parece corresponder à expectativa da autora, que, para ela, suas memórias, embora "imaginadas por sua mente infantil", são "fatos". Testemunha de eventos que marcaram sua vida individual e familiar, a partir do referido casamento de sua mãe, em 1920, Ingrid Koster, nome de solteira, tece uma narrativa na qual comparecem diversos elementos, entre os quais destacamos: a morte precoce de seu pai biológico, quando ela ainda era bebê e o novo casamento de sua mãe; a eclosão da Segunda Guerra Mundial e sua repercussão no Brasil e na família; a prisão do pai na Ilha Grande, no Rio de Janeiro, como suspeito de espionagem nazista e a consequente dificuldade financeira que só se resolveria muitos anos mais tarde; seus anos na maturidade.

Escrito com a pretensão de publicá-lo em livro, seu manuscrito, assim como seu depoimento oral, são relatos de uma testemunha "banal", "comum", que conta sua história de vida, suas experiências que, se por um lado, não sustentam uma Verdade, permitem emergir verdades subjetivas (SARLO, 2007, p. 51). A verdade, nesse contexto, não se refere à verdade factual, objetiva ou submetida à prova (seja científica ou jurídica).

\begin{abstract}
A verdade passa a incorporar um vínculo direto com a subjetividade/profundidade desse indivíduo, exprimindo-se na categoria sinceridade e ganhando, ela mesma, uma dimensão fragmentada e impossível de sofrer controles absolutos. A verdade, não mais unitária, [...] passa a ser pensada em sentido plural, como são plurais as vidas individuais, como é plural e diferenciada a memória que registra os acontecimentos da vida (GOMES, 2004, p. 14).
\end{abstract}

2 Usaremos o termo textos da memória para referirmo-nos aos manuscritos da autora, bem como aos seus relatos orais. Salientamos que o manuscrito foi escrito ao longo de um período de sua vida, que tomou alguns anos, por isso não tem data precisa e demarcada. Ingrid Koster inicia seu manuscrito no início dos anos 2000, quando então já era uma senhora de mais de 70 anos, visto que nascera em 1928. Em 2009, gravou sua história de vida em relato oral, como parte da confecção do livro Ingrid, uma história de exílios. 
Ao tomar a palavra, Ingrid Koster contribui para que possamos conhecer as microhistórias da sua vida, as quais têm tido escuta tanto acadêmica, quanto midiática, nas últimas décadas (SARLO, 2007, p. 56). Histórias de pessoas comuns, contadas ou escritas por elas mesmas, abrem um debate sobre a escrita autorreferencial ou a escrita de si. Legitimam-se os procedimentos de produção ou de guarda de uma memória individual, ou seja, das pessoas comuns, cujos registros de suas memórias são subjetivos, comuns como suas vidas e legítimos como "desejo de registro do homem 'anônimo', do indivíduo 'comum', cuja vida é composta por acontecimentos cotidianos, mas não menos fundamentais a partir da ótica da produção de si" (GOMES, 2004, p. 13).

Com título provisório, Meu pai, um espião?, no início dos anos 2000, o manuscrito de Ingrid totaliza 63 páginas e serviu de fonte primária para a produção do livro, renomeado para Ingrid, uma história de exílios, publicado em 2010, com 261 páginas, pela editora Sagui, em São Paulo. Permeando as duas produções, ainda temos seu relato oral sobre sua história de vida, gravado em vídeo em 2009, na sua casa.

Temos, assim, três diferentes mídias: a primeira, o manuscrito; a segunda, seu depoimento, o texto da oralidade em que a autora conta, em entrevista, sua história de vida e, finalmente, a terceira, a midiatização propriamente dita, quando as memórias de Ingrid transformam-se em livro romanceado, com contextualização histórica e texto reelaborado, realizados por um redator, uma historiadora e a própria Ingrid. Nas três situações, a autora é a narradora em primeira pessoa, no entanto, no livro romanceado existe um redator que não apenas organiza o texto original, mas o reelabora e o reescreve por meio da assessoria histórica.

A memória, portanto, atravessa três formas de expressão e a análise sobre a construção das memórias por essas expressões, vistas aqui como diferentes mídias (devido aos diferentes suportes e linguagens), torna-se o propósito desse artigo. Dessa forma, temos como objetivo verificar nos diferentes textos da memória de Ingrid Koster suas adaptações, seus silenciamentos e seus acréscimos, diante das diversas formas de produção das mídias e de construção da memória.

\section{Os textos da memória}

A narrativa apresenta duas temáticas distintas, que têm a Segunda Guerra Mundial, seus antecedentes e seus desdobramentos, como divisor. Na primeira parte, são apresentadas a infância em Rio Negro, no Paraná, e em Joinville, em Santa Catarina; a eclosão do conflito mundial e a prisão do pai adotivo - o padrasto. A segunda parte coincide com o período pós-guerra, o retorno do pai ao lar após três anos preso em Joinville e no Rio de Janeiro, o diagnóstico e o agravamento da esquizofrenia da mãe, a mudança definitiva para São Paulo e a luta pela sobrevivência financeira.

Seu pai é o fio condutor da narrativa que estamos chamando de primeira parte, que vai de 1920, ao celebrar o segundo casamento da mãe de Ingrid com seu padrasto, 
até 1945, quando é libertado. Ele comparece nas linhas iniciais da primeira página do manuscrito, quando o casamento de sua mãe é anunciado e sua admiração por ele é imediatamente revelada ao leitor: "Eu teria um pai também, igual ao de minhas amigas! Mas havia uma diferença - ele era mais alto, mais inteligente e muito mais bonito que o delas" (manuscrito, s/d, p. 1). O afeto pelo pai e a reciprocidade que sentia praticamente fecham as memórias da infância, quando eclode a Segunda Grande Guerra.

Quando escreve a data de 1\%09/1939 (manuscrito, s/d., p. 9), Ingrid compartilha a tensão que passa a reconhecer no pai e que vai aumentando à medida que a guerra repercute no Brasil: "Começava a segunda guerra mundial com a invasão da Polônia pela Alemanha. Seria esse o motivo de preocupação que eu via nos olhos de meu pai? "3. Ainda na mesma passagem, reproduz a resposta dele sobre os motivos que começam a afetar a vida da família e que mal conseguia compreender:

A guerra na Alemanha tem muito a ver conosco, sim, dependendo dos acontecimentos, dos rumos que as coisas tomarem. Eu sou estrangeiro, você sabe, e acontece que meu país resolveu começar uma guerra cujas consequências talvez dependam o nosso futuro (manuscrito, s/d, p. 10).

Talvez essa seja uma das páginas mais importantes do manuscrito, uma vez que, pelo encadeamento das lembranças despertadas pela eclosão da guerra, surge, logo na sequência e pela primeira vez, a descrição e as dúvidas sobre o envolvimento do pai como espião, não mais pela ótica infantil, mas pela de Ingrid, já adulta:

Relembrando este momento e, comparando com as pesquisas nas quais eu avidamente mergulhei, não deixei de perceber certas singularidades, coincidências talvez, do envolvimento de meu pai no seu trabalho. Teria sido ele realmente um espião ou colaborador a serviço da Alemanha?4 (manuscrito, s/d, p. 11).

O que estamos denominando "segunda parte" do manuscrito inicia-se com a data de abril de 1945, quando chega a suas mãos um cartão escrito pelo pai, ainda no Rio de Janeiro, que avisava sobre a sua libertação do Campo de Concentração da Ilha Grande, instalado dentro do presídio Cândido Mendes para receber os estrangeiros originários do Eixo, naquele momento em guerra com o Brasil. Suas tentativas em saber do pai o que Ihe acontecera na prisão jamais foram bem-sucedidas, como mostra o diálogo abaixo:

Você nunca quis falar sobre o assunto, mas eu gostaria de saber se você teve de fato algo a ver sobre espionagem na época da guerra... sobre tua prisão...

Hesitou um pouco antes de responder:

-- Veja bem, filha. [...], meu chefe, que você conheceu, tinha sim um rádio transmissor no porão de sua casa, e ele foi preso e condenado, mas eu não...

3 Itálico da autora.

4 Itálico da autora. 
eu não fui condenado.

Simples assim. (manuscrito, s/d., p. 62).

Tal excerto mostra a construção da memória da autora-narradora, especialmente daquilo que ela quer contar e silenciar:

A pergunta seguinte pairou nos meus lábios. Se eu insistisse: "Mas você foi espião?!!. Ele com certeza responderia "sim" ou "não", mas a coragem me faltou. Tive pena daquele homem, meu pai, tão doente e alquebrado, não quis fazê-lo dizer algo que talvez quisesse silenciar. Talvez também eu, no meu íntimo, não quisesse saber a verdade, caso ela existisse (manuscrito, s.d., p. 62).

Ao se converter em sujeito comunicável, Ingrid coloca em "comum" sua experiência. Esse parece ser o papel dos seus textos da memória, seja pela narrativa escrita, seja pela oralidade.

O relato oral de sua história de vida se constituiu em 2009, quando Ingrid relatou os mesmos episódios do manuscrito, evocando suas lembranças por meio de algumas fotografias da família, dos tempos de menina, das cidades onde morou e das práticas culturais alemãs, advindas das suas origens. Esse relato oral somou-se ao manuscrito, constituindo o texto da memória, aquele em que Ingrid é, sozinha, autora, personagem e detentora da memória que quer reconstruir. Esses relatos ocorreram enquanto se elaborava o livro Ingrid, uma história de exílios, como produto editorial e entravam em cena novos sujeitos para a construção da memória de Ingrid (o redator, que alterou o título original, e a historiadora que serão tratados a seguir).

A narrativa circunscreve a experiência num tempo. Não é o tempo em que se conta a história, mas o tempo em que se passa a história, é o tempo recordado. Eis que se estabelece então uma imbricada relação de temporalidades na construção dessa narrativa oral, diferentemente da narrativa dos textos escritos (do manuscrito e do livro), pois vários tempos se encontram: o presente da narração, o passado da história e o presente que vê e reconstrói o passado, numa relação entre lembrar e reviver: o que se vive é o que se relata e o que se relata é o que vive (SARLO, 2007, p. 33). Pois que, na escrita de si, ou mesmo na narrativa oral, o indivíduo é, da mesma forma, uno e múltiplo e, ainda, fragmentado, por isso "experimenta temporalidades diversas em sentido diacrônico e sincrônico. As práticas da escrita de si podem evidenciar [...] como uma trajetória individual tem um percurso que se altera ao longo do tempo, que decorre por sucessão" (GOMES, 2004, p. 13).

\section{Ingrid, uma história de exílios}

Romanceado "dos originais" (manuscrito) de Ingrid Koster, por Marcílio Godoi, com pesquisa histórica de uma especialista, apoiado ainda em depoimento oral sobre sua história de vida, o livro Ingrid, uma história de exílios, anteriormente intitulado Meu pai, um espião?, foi publicado em 2010 pela editora Sagui, em São Paulo. 
A alteração dos títulos anuncia o protocolo de leitura de Marcílio Godoi sobre a trajetória de vida de Ingrid Koster: sobressaem-se as descontinuidades, os deslocamentos, o sentimento de que "são os outros que pertencem àquele meio e não ele" (SAID, 2003, p. 54).

Ingrid experimenta o "exílio dentro do exílio", ao vivenciar a imediata exclusão pelos colegas e pela direção da escola onde estudava, quando a prisão de seu pai se torna pública. A menina substitui a sensação de amparo e pertencimento onde vivia com sua família em Joinville, pela de exilada, tão bem descrita por Edward Said (2005, p. 55): "[...] ser uma espécie de pária permanente, alguém que nunca se sentia em casa, sempre em conflito com o ambiente que o cercava, inconsolável em relação ao passado, amargo perante o presente e o futuro".

Os títulos marcam, frente ao texto manuscrito e no seu deslizamento para o produto livro, a interferência direta do editor. Não se trata mais de uma narrativa contada em primeira pessoa, em que o destaque recaía sobre a duvidosa atuação do pai da protagonista, mas de uma história que privilegia sentimentos de terceiros, como se tivessem sido resultado de pesquisa e não de um relato de vida. Isso tornou o livro um produto midiático híbrido no que diz respeito às questões de sua autoria e mesmo de sua confecção. Marcílio Godoi foi o responsável pela escritura, enquanto a historiadora e Ingrid participavam da redação com ajustes e comentários sobre o contexto da História e da vida da personagem.

No entanto, a participação e presença de Ingrid Koster na produção do livro, insere-se, como Angela de Castro Gomes (2004, p. 16) defende, de que "a escrita de si é, ao mesmo tempo, constitutiva da identidade de seu autor e do texto, que se criam, simultaneamente, através dessa modalidade de 'produção do eu'".

Embora com pouca distribuição, uma vez que ainda está na primeira edição, ocorreu com ele e com os textos que o precederam um processo, identificado por Lucia Santaella em meados dos anos 1990, de trânsito entre as mídias, pois "as mesmas informações vêm transitando de uma mídia para outra e distribuem-se em aparições diferenciadas: rádio, televisão, jornais, revistas, documentários, etc." (SANTAELLA, 2003a, p. 53). Trata-se da cultura midiática (ou cultura das mídias) que torna os trânsitos tão fluídos, que não mais se interrompem dentro de uma esfera específica (erudita ou popular); ao contrário: colocam tudo em movimento e aceleram "o tráfego entre suas múltiplas formas, níveis, setores, tempos e espaços" (SANTAELLA, 2003a, p. 53).

Os textos da memória de Ingrid, que migraram para o livro, sofreram as necessárias adaptações. Trechos foram acrescentados, outros, suprimidos, a linguagem bastante alterada, para atender às expectativas do redator sobre livros de sucesso, haja vista, por exemplo, a descrição detalhada da primeira aparição do pai de Ingrid:

Quando o vi pela primeira vez, ele estava do outro lado da rua. Minha mãe e eu, menina, juntas no portão de casa, ansiávamos entre esperançosos gerânios 
e malvas esparsas pelos passos seguintes daquele homem que trazia consigo a continuação de nossa história parada no tempo. [...] (GODOI, 2010, p. 8). ${ }^{5}$

Não bastassem os desnecessários nomes das flores e suas respectivas qualidades, o que nos chama a atenção, enquanto acréscimo, é o final do primeiro período: "continuação de nossa história parada no tempo". Em nenhum momento dos textos da memória Ingrid comenta que, entre a morte de seu pai biológico e o segundo casamento de sua mãe, isto é, nos seus primeiros cinco anos, a vida de ambas "havia parado". Ao contrário, "A minha primeira infância foi particularmente feliz. [...] Foi a melhor época da minha vida, da qual, apesar de minha pouca idade, lembro nos mínimos detalhes" (manuscrito, s/d., p. 1).

Mais uma vez não se trata de discutir a Verdade, como Beatriz Sarlo (2007) e Angela de Castro Gomes (2004), mas ponderar em que medida cabe aos autores do livro (redator, historiadora e Ingrid) acrescentar informações que não correspondam aos episódios relatados nos textos da memória.

Consideramos que tanto o manuscrito quanto o produto midiático livro, embora diferentes no título, na estrutura, nos narradores e na linguagem, são produtos de uma mesma cultura e fazem parte do seu continuum, isto é, "[da cultura] cumulativa, não no sentido linear, mas no sentido de interação incessante de tradição e mudança, persistência e transformação" (SANTAELLA, 2003b, p. 1).

A profusão de produtos culturais é uma manifestação do que ocorre na cultura das mídias, fenômeno identificado por Lucia Santaella em 1992, cuja dinâmica possibilita aos seus consumidores interferir e escolher os produtos simbólicos, ampliar os mercados culturais e expandir os hábitos de consumo de cultura. Quando uma mídia desliza para outra, como observamos na escrita de Marcilio Godoi, formam-se redes de complementaridade entre os meios, sem necessidade de priorizar seus usos nem os sentidos sobre os signos (2003b, p. 1).

Para Walter Benjamin, articular o passado não significa conhecê-lo como ele obrigatoriamente ocorreu, mas "apoderar-se de uma lembrança tal como ela cintila num instante de perigo" (apud GAGNEBIN, 2006, p. 40). Para o filósofo alemão é impossível haver correspondência exata entre discurso científico e fatos históricos (tais como as classificações de Lineu, por exemplo), uma vez que os fatos históricos ganharam esse status apenas porque um discurso os constituiu enquanto tais. $\mathrm{Ou}$, dito de outra maneira pelo historiador Pierre Vidal-Naquet: "na falta de algo melhor, chamamos [o fato] de real" (apud GAGNEBIN, 2006, p. 40).

É meritório que uma mulher viúva e sua filha tenham conseguido se manter econômica e emocionalmente por cinco anos, numa sociedade patriarcal como a da época, sem a presença de um marido, o que ocorreria somente em 1920 com o segundo casamento

5 Todos os nomes que aparecem, tanto no livro, quanto no manuscrito, são fictícios. Ingrid Koster sempre preferiu manter o anonimato de seus parentes e amigos citados em seus textos. 
da mãe de Ingrid. Assim, parece uma irreverência do redator acrescentar algo não narrado nos textos da memória, mas que foram escritos por sua própria imaginação, deixando o texto do livro na fronteira entre verdade e ficção. Reconhecemos, com Sarlo (2007, p. 57), que inexiste uma relação direta entre o direito de recordar e a verdade de uma recordação, e também com Walter Benjamin e Vidal-Naquet (apud GAGNEBIN, 2006, p. 40) de que o "fato" e o "real" são construções narrativas.

Sabemos que o redator leu os textos da memória de Ingrid e acrescentou outros elementos que julgou convenientes para dar sustentação à história ou mesmo apelo comercial. Portanto, conjugou narrativas que o precederam, sem mesmo se dar conta delas e as acionou quando escreveu o livro, considerando, ainda, que episódios da história de Ingrid foram contextualizados na História dos alemães no Brasil. Um dos momentos em que se percebe essa conjugação refere-se ao que o redator nomeia de "memoricídio familiar" (GODOI, 2010, p. 83), ou seja, a ocasião em que livros, fotos, discos e documentos da família alemã foram queimados numa fogueira no quintal da casa em Joinville: "em meio às imensas chamas que subiam viam-se arder não apenas seu passado, mas todo o nosso futuro de recordações e autorreconhecimento" (GODOI, 2010, p. 84).

Como Ecléa Bosi explica:

Quando um acontecimento político mexe com a cabeça de um determinado grupo social, a memória de cada um de seus membros é afetada pela interpretação que a ideologia dominante dá desse acontecimento. Portanto, uma das faces da memória pública tende a permear as consciências individuais (BOSI, 2003, p. 22).

Também é preciso ressaltar que as contextualizações históricas, que permeiam o texto do livro, não foram produzidas como fruto das recordações de um passado vivido e atualizado no presente, mas de pesquisas documentais, coletadas por uma historiadora. Isso faz do próprio texto um produto híbrido, em que não se reconhecem, com nitidez, os limites entre autobiografia, ficção e pesquisa documental, o que, se por um lado, não compromete sua qualidade, por outro, indica os atravessamentos e deslizamentos pelos quais a memória de Ingrid passou entre os textos da memória até o produto editorial final.

Em comum em todos os registros, mas com ênfase muito maior nos textos da memória, a pergunta que perseguiu Ingrid, e à qual ela nunca conseguiu responder, foi sobre a participação de seu pai, junto ao governo alemão, durante a Segunda Guerra. Sua evocação do passado é necessária para afirmar sua identidade, tanto como indivíduo, quanto de grupo, isto é, dos "súditos do eixo", familiar etc.:

Sem dúvida, um e outro [indivíduo e grupo] também se definem no presente e seus projetos no futuro: Se recebermos uma revelação brutal sobre o passado, que nos obrigue a reinterpretar radicalmente a imagem que fazíamos dos nossos próximos e de nós mesmos, não é um compartimento isolado de nosso ser que fica alterado, mas nossa identidade mesma (TODOROV, 2002, p. 195). 
O chefe do pai de Ingrid "era um dos mais importantes executivos alemães no Brasil. Ele coordenava uma equipe de profissionais espalhados por todas as regiões [...]" (GODOI, 2010, p. 42). Um dos amigos mais prestigiosos dele era chefe do Partido Nazista no Brasil, mais conhecido por seu cargo como adido cultural da embaixada alemã. Sempre viajavam para a Alemanha. "Certamente eram afinadíssimos com o Terceiro Reich" (GODOI, 2010, p. 42).

Seu pai nunca foi antinazista, o que pode ser explicado pelo sentimento compartilhado por muitos imigrantes alemães no exterior, a partir da década de 1920, quando a Alemanha saiu totalmente destruída da Primeira Grande Guerra e tentava se reerguer econômica e politicamente:

Um espião é muito mais comum do que se pode imaginar. Descobri que são pessoas muito diferentes daqueles charmosos agentes secretos que os filmes se esmeraram em construir nos tempos depois da guerra. Para atuar no Brasil, durante o período em torno da Segunda Guerra Mundial, os espiões alemães eram escolhidos e arregimentados entre os próprios imigrantes ou estrangeiros que moravam no Brasil (GODOI, 2010, p. 80).

Apesar de a identidade ser sempre movediça e múltipla e nunca única e rígida (TODOROV, 2002, p. 195), vivemos no meio de outros grupos sociais. Ingrid relatou, em diversos momentos, seu mal-estar todas as vezes em que seu pai era citado como prisioneiro de guerra, especialmente quando frequentava a escola. Se ainda fosse comprovada, publicamente, sua suspeita de que era espião nazista, certamente sua crise identitária seria mais intensa, não só como cidadã brasileira, mas como filha de um pai que tinha como ídolo.

\section{A redenção pelos textos da memória}

Beatriz Sarlo (2007) comenta que a sociologia da cultura, graças ao trabalho de Richard Hoggart, de meados de 1950, valorizou a importância do relato do passado de pessoas comuns, e o discurso indireto livre e da primeira pessoa, pela literatura. Passaram, portanto, a ser objeto de investigação a vida doméstica dessas pessoas, a administração dos seus gastos em tempos de escassez, suas férias etc., nas diversas mídias que lhes dão suporte e são atravessadas.

Todos esses componentes encontram-se nos textos de Ingrid. No entanto, apenas nos textos do livro e da oralidade comparecem uma figura central de sua vida, que é esquecida no texto do manuscrito: a querida prima Gerda. Durante a infância, Ingrid fora informada de que ela havia falecido subitamente de um mal qualquer. Apenas na vida adulta, soube que fora expulsa da família porque engravidara e não pudera se casar com o pai da criança. 
A memória é um campo de conflitos, "opera com grande liberdade, escolhendo acontecimentos no espaço e no tempo" (BOSI, 2003, p. 31). A omissão de Gerda no manuscrito, uma pessoa tão importante na vida de Ingrid, pode sugerir que sua "marginalidade" moral para os anos 1930 a fez esquecê-la, porque era muito doloroso lembrar-se de um luto que nunca houve. No entanto, foi apenas com o seu depoimento para a confecção do texto do livro, em 2009, que Ingrid conseguiu se curar dessa ferida e que finalmente a história veio à tona: "A narrativa é terapêutica" (BOSI, 2003, p. 34).

Para Walter Bejamin (1995, p. 269), a cura por meio da narrativa é tão poderosa que ele se pergunta se "não seriam todas as doenças curáveis se apenas se deixassem flutuar para bem longe -- até a foz -- na correnteza da narração".

Lembramos o relato de Tzvetan Todorov (2002, p. 199) sobre Jorge Semprun, sobrevivente do campo de Buchenwald, que "foi praticamente salvo pelo esquecimento de sua experiência concentracionária. No plano individual, cada um tem o direito de decidir sobre isso". O esquecimento também pode ser um afastamento da consciência de fatos e de eventos intoleráveis, e mantê-los nesse limbo não deixa de ser um ato em prol da saúde mental.

Da mesma forma, como já destacamos, o pai de Ingrid também se negou a contar sua história nos campos de concentração pelos quais passou no Brasil (em Joinville, na Ilha das Flores e, por último, na Ilha Grande): as torturas que deve ter sofrido, seus companheiros de confinamento, as acusações e suas ações.

Benjamin comenta sobre os sobreviventes das trincheiras da Primeira Grande Guerra, que voltaram mudos porque "aquilo que vivenciaram não podia mais ser assimilado por palavras" (GAGNEBIN, 2006, p. 50). Talvez isso explique os mecanismos que fizeram o pai de Ingrid jamais citar os outros sujeitos que, como ele, também sofreram a repressão do governo brasileiro sobre os alemães, quando o Brasil entrou na guerra contra o Eixo. As atrocidades pelas quais passou, sejam físicas ou emocionais, fizeram-no se calar. Esse esquecimento forçado do pai de Ingrid (o "memoricídio") não permitiu a cura da família por meio da narrativa. Mas, ao que nos parece, foi Ingrid quem ousou fazer a narração de uma experiência unida ao corpo e à voz, colocando-se como sujeito na cena passada. Por isso, Beatriz Sarlo (2007, p. 29) nos adverte de que não há testemunho sem experiência, nem tampouco há experiência sem a narração, pois é a linguagem que libera o sujeito de sua experiência e o redime do esquecimento (SARLO, 2007, p. 29).

\section{Considerações Finais}

Os textos aqui analisados "são inseparáveis das formas de socialização e cultura que são capazes de criar" (SANTAELLA, 2003a, p. 64). O que chama a atenção nesses três suportes é o deslizamento entre suas formas narrativas e a possibilidade de ampliar o mercado cultural, ao ganharem visibilidade comercial. 
Os textos da memória (escrito e oral) foram concebidos para registrar, inicialmente, a história de vida de uma pessoa comum. O texto desprovido de adjetivos, escrito pela testemunha, imprimiu certo ritmo de leitura e o os fatos tentaram corresponder às poucas datas que são lembradas.

O texto do livro excedeu-se em adjetivos, ampliou o número de páginas e acrescentou expressões alemãs. As datas deixaram de comparecer, mas no seu lugar há números de capítulos, como costuma ocorrer com a maior parte dos livros editados.

Todos os textos são testemunhais e a narração é em primeira pessoa, até mesmo no texto do livro, em que "Marcílio Godoi faz a mediação entre os contextos pessoal e histórico" (GODOI, 2010, orelha do livro).

Produzidos ao longo da primeira década de 2000, os três suportes da memória promovem, numa visão estrita e tradicional, sociabilidades e recepções específicas: o público que recebe o livro não teve acesso aos textos da memória (escrito e oral). No entanto, como sugere Santaella (2003a, p. 71), estamos experimentando na cultura das mídias "misturas entre as formas, gêneros, atividades, estratos e segmentos culturais e meios de distribuição e interação comunicacionais".

Como ainda lembra a autora "cada novo meio de comunicação traz consigo um ciclo natural que lhe é próprio" (SANTAELLA, 2003a, p. 64). É possível supor que filmes ou HQs, por exemplo, poderão, no futuro, ser gerados com base nos registros de Ingrid e que seus consumidores poderão interagir com eles, compartimentá-los e transformá-los. Os gêneros dos textos talvez se tornem tão híbridos que a experiência de registrar a memória exija do pesquisador uma busca de novos instrumentos conceituais, mais adequados ao mundo de hoje.

Não há uma ligação de causa e efeito entre os suportes que deram sustentação às memórias de Ingrid Koster, pois se trata, ao fim e ao cabo, de modelos de negócios. Enquanto o relato oral e o manuscrito estavam circunscritos única e exclusivamente às lembranças da autora, o produto livro procurou atender a uma demanda de mercado e inseriu o editor na posição de coautor.

As linguagens do manuscrito e do livro são isomórficas, pois se assemelham na forma e na estrutura e permitem recuperar "os fios da malha híbrida da cultura" e da memória na ausência daquele que lembra.

Não podemos deixar o passado cair no esquecimento, nem reconstruir uma grande narrativa heróica que dê continuidade histórica. Vimos que o passado não existe: ele é atualizado no presente pela narrativa.

Quando pessoas comuns escrevem suas histórias de vida, gênero textual a que nos dedicamos nesse artigo, costumam intercalar tempo presente com o passado, eventualmente projetam o futuro, mas sempre selecionam eventos significativos de suas vidas, como pudemos observar nos três suportes midiáticos de Ingrid.

Os textos da memória e do livro, com todas suas diferenças e semelhanças, despertaram o interesse da pesquisa, tanto pelo manuscrito e pelo relato oral de Ingrid, 
quanto pelo produto editorial. Embora a história fosse a mesma, os diferentes suportes midiáticos e as maneiras de contar - a emoção correndo mais solta no manuscrito, as interferências do redator, a organização em capítulos e as informações históricas -, reiteram a afirmação do jornalista Alberto Dines: "o que autentica uma biografia é a faísca que dará vida ao ser humano. A biografia não é uma coleção de documentos arranjados sob forma literária, é um coro de vozes para fazer falar a outra voz, a do biografado" (DINES, 2006, p. 178). Dito de outra forma: toda pessoa tem uma história que vale a pena ser contada, ouvida e registrada.

Já vimos que diferentes suportes articularam a construção da memória de Ingrid. No entanto, mais do que coletar e compartilhar informações sobre a memória das pessoas comuns, é necessário admitir a existência desse outro, permitir a alteridade e deixar de ignorar os que não são iguais a nós. A busca do outro será tão ou mais prazerosa quanto mais deslizantes forem os gêneros textuais e as mídias que lhes dão suporte.

\author{
Barbara Heller é professora na Unip. \\ b.heller@terra.com.br
}

Priscila Ferreira Perazzo é professora na Universidade Municipal de São Caetano do Sul.

prisperazzo2@gmail.com

\title{
Referências
}

BENJAMIN, W. Rua de Mão Única. In: Obras escolhidas. 5. ed. São Paulo: Brasiliense, 1995.

BOSI, E. O tempo vivo da memória. Ensaios de psicologia social. São Paulo: Ateliê Editorial, 2003.

DEPOIMENTO de Ingrid Helga Koster Aguiar para Marcílio Godoi e Priscila F. Perazzo. Registro em vídeo. São Paulo, 2009.

DINES, A. Em busca do outro: biografias e histórias de vida. In: WORCMAN, K.; PEREIRA, J. V. (Coord.). História falada: memória, rede e mudança social. São Paulo: SESC SP: Museus da Pessoa: Imprensa Oficial do Estado de São Paulo: 2006.

GAGNEBIN, J. Lembrar, escrever, esquecer. São Paulo: H34, 2006. Disponível: em:<http://www. hrenatoh.net/curso/textos/txt_gagnebin_jeanne_m_lembrarescrevereesquecer.pdf $>$. Acesso em: 16 fev. 2016.

GODOI, M. Ingrid, uma história de exílios. São Paulo: Sagui, 2010.

GOMES, A. C. (Org.). Escrita de si, escrita da história. Rio de Janeiro: Editora FGV, 2004.

MANUSCRITO de Ingrid Koster, intitulado Meu pai, um espião?, s/d, 63 páginas. 
SAID, E. Representações do intelectual. São Paulo: Companhia das Letras, 2005.

Reflexões sobre o exílio e outros ensaios. São Paulo: Companhia das Letras, 2003.

SANTAELLA, L. Cultura e artes do pós-humano: da cultura das mídias à cibercultura. São Paulo: Paulus, 2003a.

. Cultura em deslocamento. Mesa Redonda Cultura em Deslocamento dentro dos painéis Investigações Contemporâneas, $\mathbf{1 4}^{\mathbf{0}}$ Festival Internacional de Arte Eletrônica Videobrasil. 2003. Disponível em: <http://www.videobrasil.org.br/14/news/portopiniao/4Cultura.pdf>. Acesso em: 02 nov.2016b

SARLO, B. Tiempo pasado. Cultura de la memoria y giro subjetivo. Una discusión. Buenos Aires: Siglo Veintiuno Editores, 2007.

TODOROV, T. Memória do mal, tentação do bem: indagações sobre o século XX. Sâo Paulo: Arx, 2002.

Artigo recebido em agosto e aprovado em dezembro de 2016. 